\title{
Examining the Attitudes and Intention to Use Synchronous Distance Learning Technology among Pre-service Teachers: A Qualitative Perspective of Technology Acceptance Model
}

\author{
M.Tuncay Sarıtaş ${ }^{2, *}$, Emel Yıldız ${ }^{1}$, Hüseyin Can ŞENEL ${ }^{3}$ \\ ${ }^{1}$ Mehmetçik Secondary School, Balikesir, Turkey \\ ${ }^{2}$ Department of Instructional Technology, Balikesir University, Balikesir, Turkey \\ ${ }^{3}$ Turkish Land Forces Non-Commissioned Officer College, Balikesir, Turkey \\ *Corresponding author: tuncaysaritas@gmail.com
}

\begin{abstract}
Synchronous" distance learning environments are becoming prevalent with the rapid developments in information and communication technologies allowing participants to be actively engaged in collaborative learning activities at a distance. Innovative synchronous distance learning tools provide alternative, flexible, and rich learning opportunities, which could highly be consistent with the demands and needs of the 21st century learners. It is therefore crucial for teachers of today to develop a positive attitude toward this kind of learning environment and have an intention to use it in their work life. This study aimed at examining the attitudes of pre-service teachers toward distance education and their acceptance status of the technology supporting synchronous distance learning experience. After a four-week distance course offered by four instructors from different universities at a distance, the findings indicate that the participants developed positive attitudes toward distance education. Based on the results, we discuss the pre-service teachers who accepted this technology based on three factors: perceived usefulness, perceived ease of use, and intention to use it again.
\end{abstract}

Keywords: synchronous online courses, distance education, pre-service teachers, technology acceptance model

Cite This Article: M.Tuncay Sarıtaş, Emel Yıldız, and Hüseyin Can ŞENEL, "Examining the Attitudes and Intention to Use Synchronous Distance Learning Technology among Pre-service Teachers: A Qualitative Perspective of Technology Acceptance Model.” American Journal of Educational Research, vol. 3, no. 10A (2015): 17-25. doi: 10.12691/education-3-10A-3.

\section{Introduction}

By means of rapid developments and changes in ICT, knowledge is dispersing simultaneously, generated by every individual and accessible independent of time and place [1]. Hence, consistently renewed knowledge is enforcing individuals to be receptive for innovations and open for lifelong learning [2]. Synchronous distance learning environments, which are highly developed in recent years, are presenting learning opportunities with its educational components [3,4]. Schools and other educational institutions have started to realize its positive effects and outcomes on learning processes. A number of them have begun to transform some of their existing course systems into new designs for their educational environments, namely synchronous distance learning environments $[5,6,7]$. In that respect, along with the increase in the number of organizations that support synchronous distance learning, learners are more demanding this new style of instruction $[8,9,10,11]$.

Synchronous distance learning environments supporting multi-way audio and visual communication tools provide contexts for learners to be able to interact with others and get immediate feedback [12,13]. Advanced and welldesigned synchronous distance learning environments yield instructional advantages like motivation and supporting individual differences with the tools of file sharing [14], jointly usage of screens and software [15], interactive whiteboard applications [16], synchronous communication and writing [17]. On the other hand, all these new tools may have some attitudinal and acceptance problems from the perspective of students [18].

\section{Background}

Considering the critical drawback of distance education environments, that is, the lack of face-to-face interaction, newly and well-designed synchronous distance learning environments provide new solutions and a response to this drawback by its tools such as real-time online voice and image transfer amongst learners, file sharing, whiteboard applications, and so others [19,20]. With the help of innovative synchronous tools, learning experience at a distance is getting closer to the one in traditional classroom activities, which allow learners to create a 
feeling as being a part of the learning community $[21,22,23]$. Many studies in the field indicate that synchronous distance learning environments successfully support two critical factors - effective interaction/ communication with others and social presence in a social learning community - for the achievement of learning objectives [24,25,26].

In addition, some studies also suggested that synchronous distance learning tools are more efficient than asynchronous distance learning tools especially in creating a context where social interaction takes place $[27,28]$. From this perspective, it is important to provide online audio-visual communication channels along with non-verbal tools to develop a learning community at a distance. Synchronous distance learning environments are one of the most preferred and selected educational tools among all other distance education systems, with its characteristics that can produce a quality learning experience [29,30,31,32,33].

With the advance in technology, synchronous distance learning environments offer many advantages as mentioned above. However, attitude toward distance education and acceptance status of these environments are still arguable [33] due to the novelty effect [34,35], low levels of the media or computer literacy of the learners [36], new settlements and usage of these systems by institutions and need of continuous technical support [37], [31]. In Hart's literature review [68], 20 online learning articles were examined. According to examination results, it is found to be possible to make a group of the barriers reasoning persistence to online learning in three aspects. First barrier could be called as "technical reasons" - not being computer literate or having difficulties in accessing technological resources. Second barrier could be called as "instructional design of the courses", that is, not being able to create materials for different learning styles and/or learning objectives. For the last barrier, the term "communication failures" could be used for not having peer-to-peer communication or not having immediate feedback from the instructor. Similar results were found in different studies with various methods and techniques $[69,70]$. All these reasons may create negative attitudes against distance education. Additionally, possessing negative attitudes toward distance education could give rise to a "rejection" or "not accepting" the use of these new technologies in the future. For this reasons, this study will examine the attitudes of novice learners against distance education and further, their acceptance status of these newer technology.

\section{Technology Acceptance Model}

Adoption of different types of information and communication technologies in educational settings is still a considerable issue in terms of pedagogy and practice [38]. This problematic situation may have an effect on the quality of instructional events and activities, which can be designed and enriched by some technology products such as internet-based learning tools [39]. In this new era of technology, the notion of the acceptance and use of new technology by educators has become crucial to be able to provide rich learning resources and meaningful as well as authentic learning experiences. One of the models examining the acceptance and use of information technology is Technology Acceptance Model (TAM). This model is considered as a theoretical model to predict user behavior about one's intention to use a specific kind of ICT tool $[40,41]$. The purpose of this model is to understand the acceptability status of a newer media or tool by users [1]. This predictive and developmental model proposes that acceptability level of an innovative tool is highly ascertained by two main factors as "perceived usefulness" and "perceived ease of use" [42].

"Perceived usefulness" is defined as to what degree the new technology would contribute individuals to increase his/her job performance. These contributions may be interpreted as the decrease in completion period of the task or to develop more qualified tasks [38]. The other factor of the TAM; "perceived ease of use" is described as the thoughts or beliefs of the users to use the newer tool in a more effortless way [42]. However, [38] extended TAM as TAM2 with adding social influence factors like subjective norm, voluntariness, and image and cognitive instrumental processes like job relevance, output quality, and result demonstrability and "intention to use" as a predictor of full usage behavior as seen in Figure 1.

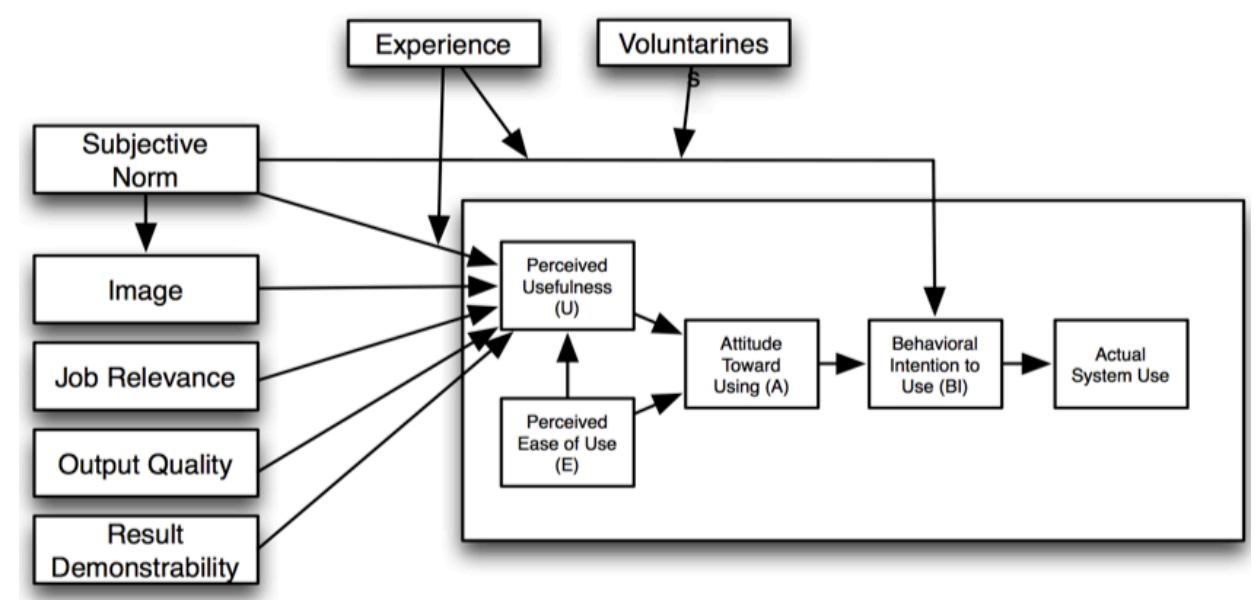

Figure 1. Technology Acceptance Model 2 [38]

A number of research expressed that TAM is a fitting model to explain the way people adopt and use new technologies in an educational setting $[43,44,45]$. In the last decade, it has documented in research studies that 
various instructional activities based on e-learning [43], online learning [45] and distance education [46] were examined by Technology Acceptance Model (TAM). However, these studies are lacking of focusing particularly on the technologies used for synchronous distance learning environments. Moreover, these studies have mainly been conducted by employing merely quantitative research methodology to collect and interpret the numerical data. Reference [47] suggested mixed method studies instead of single method studies in analyzing online learning experiences, since mixed methods approach would be more interpretive by having qualitative data explaining quantitative one.

With these in mind, this study aimed to use embedded design (mixed-method research) $[48,49,50]$ i) to explore the attitudes of the pre-service teachers about distance education through a synchronous online course and ii) to identify the acceptance status of this technology synchronous online learning and teaching tool according to three components of TAM2.

\section{Methodology}

Embedded design offers researchers to collect two kinds of data simultaneously or sequentially but analyze them separately, which addresses different research questions [50]. In this study quantitative data address whether intervention (synchronous online course) had an impact on the outcome (users' attitude on distance education), whereas the qualitative data assess how the participants experienced the intervention and their opinions about acceptance of new technology. In this form of mixed method design, qualitative phase also provides supplementary information for the first phase [48]. The research design in this study is shaped by the following research questions:

1. Is there any significant effect of using synchronous online tool on the attitudes of pre-service teachers toward distance education?

2. What is the technology acceptance status of preservice teachers about synchronous distance learning tool?

\subsection{Participants}

This study involved 15 pre-service teachers including 8 girls and 7 boys within the department of Computer Education and Instructional Technology, 4-year Faculty of Teacher Training from a middle-sized state university in Turkey. The 15 participants who registered to the HumanComputer Interaction course voluntarily accepted to participate in the study.

\subsection{Instruments}

\subsubsection{The Attitude Scale toward Distance Learning}

Attitude Scale toward Distance Learning was used as pre-test and post-test to examine whether 4-week intervention of synchronous online lessons had any impact on distance education attitudes of the pre-service teachers. Scale was developed by [51] to identify the attitudes of the university students toward distance education. Scale has 14 positive, 7 negative items and totally 21 items are gathered under six factors. Cronbach-alpha reliability coefficient was calculated as 0.835 .

\subsubsection{Interview Form}

Semi-structured interview form was developed based on Technology Acceptance Model 2 [1,38,42]. Interview questions were developed according to three factors of TAM2 addressing a) usefulness of synchronous distance learning tool, b) ease of use of the tool and c) intend: how pre-service teachers are intended to use these tools in their work life. All the interviews were conducted after 4-week synchronous online courses. The interviews, which lasted approximately 20-30 minutes for each participant, were tape recorded by researchers.

\subsection{Instructional Procedure}

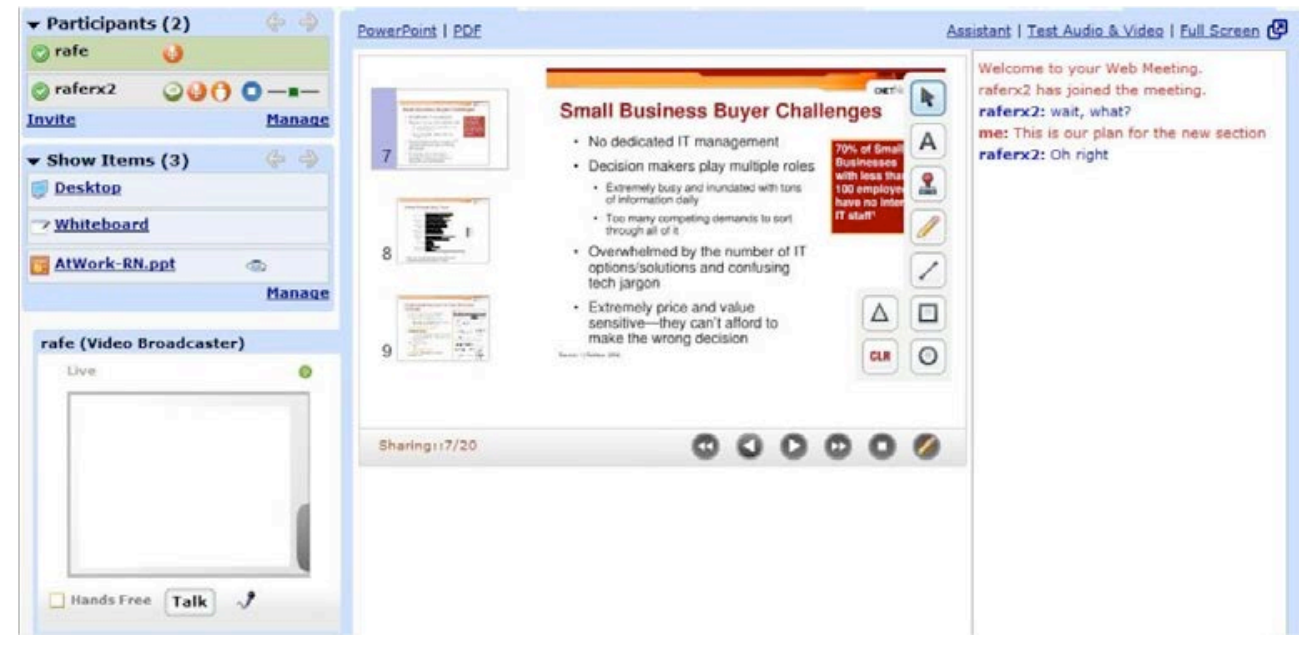

Figure 2. Integrated interface of Dimdim Webinar

Dimdim Webinar software (see Figure 2) was used in the study to provide a synchronous distance learning experience and environment for pre-service teachers. Before the synchronous online classes taking place, an instructional digital video about the technology (Dimdim
Webinar)'s tools and its use (e.g. online communication, sharing digital documents, online lecturing) was created and provided for the professors at a distance. An orientation and practical session about the utilization of 
the technology was also designed and offered for the preservice teachers at the computer lab.

Participants was provided with an opportunity to spend some time to get accustomed to the interface of the software along with the hardware including microphone, webcam and tool applications like whiteboard, chat zone and conferencing (see Figure 3 and Figure 4).

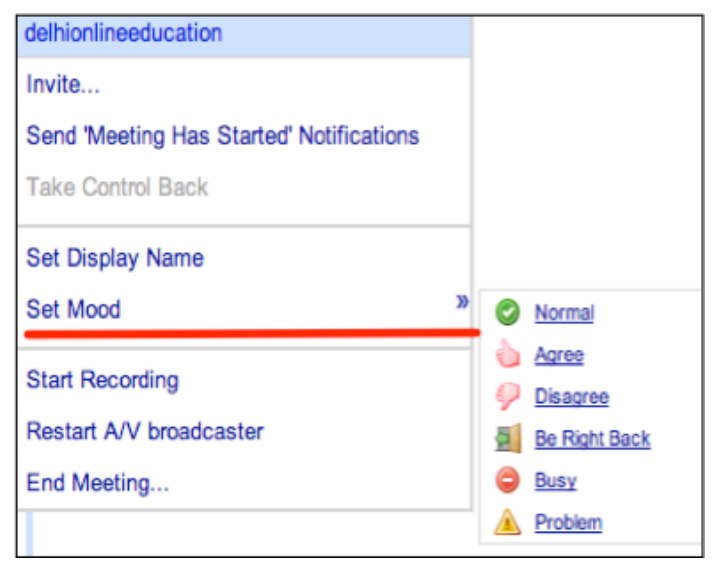

Figure 3.

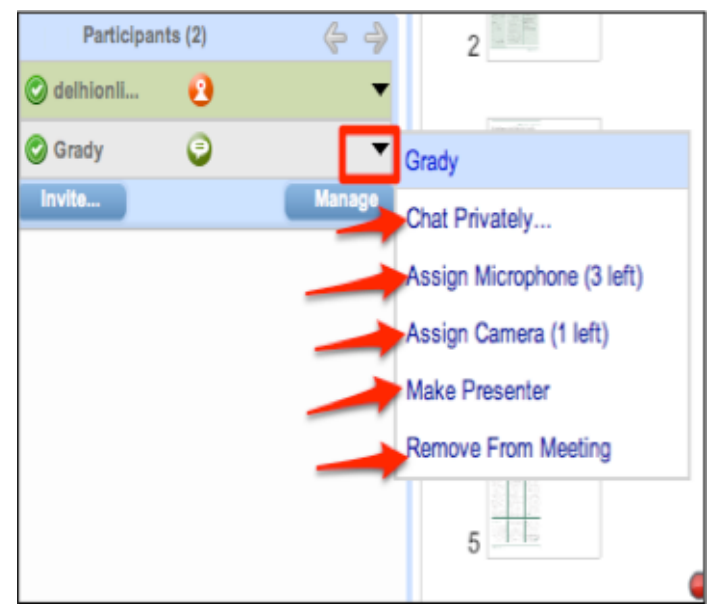

Figure 4

The four synchronous online courses lasting 1-hour was designed in four consecutive weeks. The courses was offered by four professors at four different universities at a distance - University of Nevada, Las Vegas, USA, Gazi University, Ankara, Turkey, Marmara University, Istanbul, Turkey and 19 May University, Samsun, Turkey. The professors from different universities were selected according to their expertise and research area focusing on the subject of the week. It was also contributing to students having an experience in seeing different methods of lecturing and techniques of presentation via synchronous distance technology by different professors from different locations. During the each course session, the main connection channel between professors and participants was synchronous videoconferences but whiteboard, chat zones and messages were also used.

\subsection{Data Analysis}

Wilcoxon Signed Ranked test were used to analyze the data collected from Attitude Scale Toward Distance Education. Negative items of the scale were transformed to positive ones. Score range of the scale was found to be between 21 and 105. High score predicts a positive attitude toward distance learning. For the qualitative part, a coding scheme was created by taking into account the literature and TAM2. Content analysis was conducted to analyze the qualitative data. However, before that, researchers requested confirmation from the participants whether or not the transcripts of their interviews were correctly transcribed. This feedback process is called as "member checking" [52]. In this study, amount of agreement (within the collected data) between independent data coders were used to calculate interrecorder or interanalyst reliability [71]. A second coder, a specialist in qualitative research studies as well as in the field, first got familiar with the coding scheme by practicing the coding process on the same texts that the other coder worked on. The two coders were able to identify and correct problems and create shared understanding with the coding process. After that, the second coder coded the $25 \%$ of the content and compared the results with the first coder's results. The final level of agreement between the two coders, in other words, peer review or inter-coder reliability [53] was calculated as $84,00 \%$.

\section{Results}

\subsection{Attitudes of Pre-service Teachers toward Distance Education}

According to the analysis results (see Table 1), there is a significant difference $(\mathrm{z}=2,48, \mathrm{p}<0,05)$ in terms of the attitudes of the pre-service teachers toward distance education before and after the four-week synchronous online courses. The results indicate that positive attitude was developed by the participants toward distance education after the synchronous online courses (mean score of pre-test is 26, 67 whereas it is 33,80 for post-test). When observed frequencies is considered, the score of one student is the same in both tests, 2 students have higher scores in pre-test and 12 students have higher scores in the post-test.

Table 1. Wilcoxon Signed Rank Test Results

\begin{tabular}{cccccc}
\hline & n & Mean & S & Min & Max \\
\hline Pretest & 15 & 26,6667 & 8,45718 & 12 & 41 \\
Posttest & 15 & 33,80 & 4,49126 & 27 & 43 \\
\hline $\begin{array}{c}\text { Pretest } \\
\text { Posttest }\end{array}$ & $\mathbf{n}$ & Mean Rank & Sum of Ranks & $\mathbf{z}$ & $\mathbf{p}$ \\
\hline Negative Ranks & 2 & 6,50 & 13 & 2,48 & 0,013 \\
\hline Positive Ranks & 12 & 7,67 & 92 & & \\
\hline Ties & 1 & & & & \\
\hline
\end{tabular}

\subsection{Technology Acceptance Status of Pre- service Teachers}

All of 15 pre-service teachers in the study were novice to distance education and practiced a synchronous online learning tool for the first time. Interviews were conducted about the usefulness of the synchronous distance tool, its ease of use and participants' intend to use these kinds of tools again in future.In this phase of the study, content analysis was used to analyze qualitative data. Content analysis aims defining the possible variables hidden in the data and discovering their relations with each other 
$[53,54]$. Codes that are gained from data using content analysis were gathered around the themes (see Table 2), which are generated based on TAM2 and subthemes/categories by the literature [1,38,42].

Table 2. Content Analysis Coding Scheme

\begin{tabular}{|l|l|l|}
\hline Perceived Usefulness & Perceived Ease of Use & Intent to Use \\
\hline Increase in learning performance (sub-theme 1) & Ease of learning to use (sub-theme 5) & Desire to use again (sub-theme 8) \\
Effective learning environment (sub-theme 2) & Ease of practice (sub-theme 6) & Advising system (sub-theme 9) \\
Effective time planning (sub-theme 3) & Ease of gaining acquisition (sub-theme 7) & Thought about usage increase (sub-theme 10) \\
Other Benefits (sub-theme 4)
\end{tabular}

Other Benefits (sub-theme 4)

Three main components of the TAM2, perceived usefulness, perceived ease of use and intention to use were determined as three themes for coding. Percentages and frequencies are calculated and tabulated for each subcategory (see Table 3). According to the results, it is found that "perceived usefulness" of synchronous online environments shows the highest rate of 59,30\%. "Perceived ease of use" (24,41\%) and "intention to use" $(16,28 \%)$ are two other themes. 12 out of 15 participants put a high emphasis on "perceived usefulness". "Effective learning environment" category/sub-theme is the most mentioned category in "perceived usefulness" theme. "Ease of learning to use" sub-theme is the most mentioned category in "perceived ease of use" theme and "Increase in use by others" and "recommendation" categories are the most popular categories in "intend to use" theme (see Table 3).

\subsubsection{Perceived Usefulness}

First sub-category related with perceived usefulness is “increase in learning performance” (25,49 \%). Participants interpret the applications of synchronous tools as contributing components for learning performance. Tools providing immediate feedback and peer-to-peer communication like chat or message present high motivation for participants. Codes of this sub-theme were listed as increase in motivation (code 1.1), cognitive support (code 1.2) and active participation (code 1.3).

"In classroom settings, since we must both listen to the instructor and watch the slides, we may have hard times to focus. Sometimes we cannot see or read the graphs or writings in the slides. However, we have both the speakers and headphones in software. These individual tools support concentration and motivation (code 1.1).” (P001stands for participant number one)

Students also declared that they have high motivation on using this tool that give rise to a positive impact on their attendances to the class.

"Since this is a new educational tool, learners may show more attention to courses (code 1.1) and this may increase the attendance rates.” (P007)

"I think that chat window; participation opportunities and possibility of talking peer to peer (code 2.4) may attract students' attention and motivation (code 1.1)" (P009)

Students were also positively reinforced and attracted by direct interaction with the instructor. In addition, they stated that they have similar social communication and presence as they are in traditional classroom since synchronous tools allow participants to have instant communication with other attendees. Furthermore, private messages encourage participants to ask any kind of questions without hesitation.

"Tool allows us to get into the lesson (code 1.3) and it is quite important to ask our questions immediately for our learning performances”. (P010)

"Ibelieve that getting immediate feedback (code2.4) from professors is supporting my learning performance (code 1.2)" (P006)

"In addition, we may zoom into the presentations via our computer screens. It feels like I am taking private (one to one) course (code 1.2).” (P001)

Table 3. Frequencies (f) and percentages (p) of theme, sub-themes and codes

\begin{tabular}{|c|c|c|c|c|}
\hline & Sub-themes & Codes & $\mathrm{f}$ & $\mathrm{p}$ \\
\hline \multirow{13}{*}{ Perceived Usefulness \%59,30 } & \multirow{3}{*}{ Increase in learning performance } & increase in motivation & 6 & \multirow{3}{*}{$25,49 \%$} \\
\hline & & cognitive support & 3 & \\
\hline & & active participation & 4 & \\
\hline & \multirow{4}{*}{ Effective learning environment } & technology integration & 3 & \multirow{4}{*}{$45,10 \%$} \\
\hline & & instructional methods & 5 & \\
\hline & & multimedia use & 8 & \\
\hline & & immediate feedback & 7 & \\
\hline & \multirow{2}{*}{ Effective time planning } & time management & 2 & \multirow{2}{*}{$9,80 \%$} \\
\hline & & time saving & 3 & \\
\hline & \multirow{4}{*}{ Other Benefits } & equality of opportunity & 2 & \multirow{4}{*}{$19,61 \%$} \\
\hline & & interaction with others & 4 & \\
\hline & & economical & 2 & \\
\hline & & reusability & 2 & \\
\hline \multirow{6}{*}{ Perceived Ease of Use \%24,41 } & \multirow{3}{*}{ Ease of learning to use } & user-friendly interface & 5 & \multirow{3}{*}{$57,14 \%$} \\
\hline & & catchy option menu & 3 & \\
\hline & & simple structure & 4 & \\
\hline & Ease of practice & ease use of applications & 4 & $19,05 \%$ \\
\hline & \multirow{2}{*}{ Ease of acquisition } & learning to ask focused questions & 3 & \multirow{2}{*}{$23,81 \%$} \\
\hline & & learning to attend a web conference & 2 & \\
\hline \multirow{5}{*}{ Intend to Use \%16,28 } & Desire to use again & desire to use again & 4 & $28,57 \%$ \\
\hline & \multirow{2}{*}{ Recommendation } & recommend to colleagues & 3 & \multirow{2}{*}{$35,71 \%$} \\
\hline & & recommend to administrators & 2 & \\
\hline & \multirow{2}{*}{ Increase in use by others } & technology development & 3 & \multirow{2}{*}{$35,71 \%$} \\
\hline & & individual development & 2 & \\
\hline
\end{tabular}


Pre-service teachers stated that synchronous online environments could be an "effective learning environment" $(45,10 \%)$. In terms of effective learning environment, technology integration (code 2.1), instructional methods (code 2.2), multimedia use (code 2.3) and immediate feedback (code 2.4) are the codes that participants emphasized as the benefits of the synchronous tools. However, it should be taken into account that participants used synchronous online tools (e.g., web conferences with different instructors) for the first time in their school time. Hence, the percentages herein could be defined as a "novelty effect" [34,35]. Quotations are given below related to the "effective learning environment" sub-theme.

"Synchronous environment may allow students to get involved in instructional events if the instructor uses the technological tools effectively (code 2.1), learners may profit more from applications of this kind of tool”. (P004)

Another participant (P001) declares the importance of different learning methods that instructors employed.

"I thought that it improves the effectiveness of learning process by having different viewpoints and various techniques or instructional methods (code 2.2) of different instructors; and how they differently use this technology (code 2.1)”. (P001)

"If the required background for learning is wellprepared, it is quite possible that it will be a more efficient learning environment when it is compared with conventional settings. This tool contains all the applications of classroom settings. Tool supports face-toface communication (code 2.4) with peers and instructor, helps instructor share course materials like slides, videos, web sites (code 2.3). Generally, we may not have chance to share our individual ideas to our instructors but we have chance to send special text message to our instructors (code 2.4)”. (P003)

"Since it (tool) has the potential to ask questions any time and getting answers immediately (code 2.4) students may learn efficiently and faster (code 2.3)” (P005)

The third sub-category of the perceived usefulness theme is "effective time planning" with 9,80\%. Preservice teachers' evaluates time management (code 3.1) and time saving (code 3.2) as valuable sides of the synchronous online tool.

"It is impossible to ignore time savings that synchronous tool offer. It helps us to manage time according to our daily plans (code 3.1) and also have savings economically.” (P010)

"After students get used to this tool, transmission speed between participants may increase and I believe that if all the technical background is well prepared, serious time savings may be gained (code 3.2)”. (P007)

Under the "perceived usefulness" theme, participants recognized "other benefits" $(19,61 \%)$ as equality of opportunity (Code 4.1), interaction with others (Code 4.2), economical (Code 4.3) and reusability (Code 4.4), Some of these codes could be found in the literature as the common advantages of distance education or synchronous learning $[2,55,56]$. On the other hand, "interaction with others" code is a new emerging code within this study.

"This tool has the potential to enrich the learning environment due to its characteristics of having participants from both domestic and international universities (code 4.2). In addition, it is new and different for us to have audio and visual elements in courseware that we may use repeatedly (code 4.4). These new tools encourage learners, especially for the ones who are physically handicapped for education (code 4.1). This feature of the tool impressed me a lot. Another issue is that applications of the tool may create great benefits financially and in time with the reuse of sources and the attendance rates (code 4.3 and 3.2).”(P002)

\subsubsection{Perceived Ease of Use}

In terms of perceived ease of use of the synchronous online learning tool, three subthemes were emerged: i) ease of learning to use $(57,14 \%)$, ii) ease of practice $(19,05 \%)$, and iii) ease of acquisition (23,81\%). Participants generally declared that it is easy to learn how to use the tool. Codes of this sub-theme are user-friendly interface (code 5.1), catchy option menu (code 5.2) and simple structure (code 5.3). They stated that they had no problems to get familiar with the interface and it is easy to recognize and recall menu tools.

“Although we have some problems at first glance what the tool is and how to use it, this problematic situation did not take so long since it has a user-friendly interface (code5.1) and we learned to use the system very fast.”(P008)

"I believe that anyone using Internet can also learn to use this software (code 5.1). It is very easy to learn to use it since it has only three main parts (code 5.3) and it is quite easy to remember menu options (code 5.2). It is like a simple website (code 5.3).” (P005)

Second sub-theme was found to be as "ease of practice" of the tool. Participants stated that it is also comfortable to make practice or use it during the lessons. Ease use of applications (code 6.1) is the single code of this sub-theme. Participants said that they had no problems when they were using various applications during the lessons for instance, instant messaging or chat tool.

"It was easy for me to use the tool in the lesson time. I used the message and chat tool (code 6.1) time to time during our activities and never had problems (code 5.2). I believe that being a user friendly (5.1) is a very important characteristic for this kind of tools since the only way for communication is the tool itself."(P002)

"After my first use, it was easy for me to attend online lessons. It was easy for me to use the applications like having video conferences or writing messages online (code 6.1). I think the design is simple (code 5.3) and it is good for students.”(P004)

The last sub-theme is the "ease of acquisition" including the codes - learning to ask focused questions (code 7.1) and learning to attend a web conference (code 7.2). Participants expressed that they gained some acquisitions like how to ask focused questions during the lessons or how to attend and behave in a web conference. These acquisitions may be considered as the inputs of designing and using synchronous online tools.

"Tool was giving permission to ask any questions to the instructor but sometimes we hesitate to ask since the lesson was in progress. With some tries l learned how to ask focused questions (code 7.1) or when to ask in a continuing lesson.” (P003)

"It was first time that we attend a web-conference. It was a unique experience (code 7.2) and we learned what is a web-conference is and how to connect each other." (P004) 


\subsubsection{Intention to Use}

Three sub-themes have been identified within the "intention to use" theme. The first sub-theme is created as "desire to use again" with 28,57\%. Participants affirmed that they enjoyed using the tool and had a wish to use similar tools again. Code of this sub-theme has the same name itself as desire to use again (code 8.1).

"I found the tool useful and also efficient. We used it for four weeks but l wanted to use it again (code 8.1). Maybe for some of my other lessons.” (P006)

"It was easy to use it and I find it enjoyable. Taking the course with the help of the tool was a motivation source for me. I believe this tool helped me to learn easier and 1 want to use it again (code 8.1).”(P012)

"Recommendation" (35,71\%) is another sub-theme for the intention to use of this technology among participants. Participants proclaimed that they will recommend this tool to their peers or colleagues (code 9.1). In addition, they stated that they may recommend these kinds of systems to administrators (code 9.2). Since it is enjoyable and easy to use, participants are determined to use it again with others and for some other tasks.

"Technology is improving every day. I believe we must benefit from technology. I strictly advise a synchronous system to my colleagues (code 9.1) since it is enjoyable and easy to use." (P006)

"I will use these tools in my future schools if 1 have the technical background. And 1 will also offer these tools to my administrators (code 9.2) and colleagues.” (P011)

The other sub-theme related with the intention to use is the "increase in use by others" including the codes of technology development (code 10.1) and individual development (10.2). Some of the participants noted that usage of synchronous tools will increase as the technical infrastructure is better prepared. They also advocated that the adaptation of new technologies into learning and teaching environment is an important task of being a teacher.

"I believe that these kinds of tools will be more common especially in universities in coming years as the technology develops (code 10.1). I advise synchronous tools to every student and instructor since they have many advantages especially economically.” (P015)

"In my thought, we must use these systems not to fall behind the current technology. Since we are the technology agents of the schools and providers of the new tools to the students, we must improve ourselves (code 10.2) and use the latest technologies.” (P014)

\section{Discussion and Conclusion}

Findings provided that participants have a positive attitude toward distance education after 4-week synchronous online learning experience at a distance. This result draws parallel with some other studies $[57,58,59]$. Distance education offers its users time and place independency; and supports life-long learning with its wide range of applications and fields of study [60]. In addition, technologies such as synchronous online learning tools support instructional communication and feedback at real time, interaction between student-student and instructor-student synchronously. Innovative tools of distance education systems providing numerous advantages for learning and teaching experiences could be the factors for the results in favor of positive attitude of participants toward distance education in different research studies. For instance, Reference [61] found that novice students about distance education developed positive attitude toward web conferences after their first practice of learning. The most critical and pragmatically advantage of synchronous distance environments is its ability to eliminate the most disapproving side of the distance education, that is, "perception of distance", with its tools that supports instant audio-visual communication elements [62].

Another finding within this study is that participants are eager to use the synchronous distance learning environments especially in the notion of perceived usefulness. Participants reported that synchronous online tools are beneficial especially for supporting their motivation, time managing, and effective learning. Additionally they consider these tools as supplementary tools for getting inside social communication [24,26,63]. Participants also paid attention to social communication and the importance of being a part of a social community with instant audio-visual tools [64]. In addition to academic context, participants also found chance to make social dialogues with their mates in similar tools and technologies [26,65]. However, it should be taken into account that a possible novelty effect $[34,35]$ may have an impact on the results since individuals are in response to increased interest in the new technologies. It should also be considered that gains or interests tend to decrease as students become more familiar with the new medium. With all in mind, these results may provide new strategies or tactics for instructional designers to increase the use of social communication applications and interactions for effective and efficient learning outcomes [24].

It is also found that there is no complexity in the use of synchronous distance environments; additionally the ability to use the system can be gained easily. Most of the participants expressed that they got easily familiar with the interface after the first use and declared that it is not a complicated structure hard to learn. Only two of the participants had negative considerations about the interface of the tool in terms of its lack of support in native language rather than English. On the other hand, we must emphasize that participants are pre-service teachers from instructional technology department and all of them is highly computer and media-literate individuals. It is more likely because of this, none of the participants complained about any complexity about the learning environment from a technological perspective.

Additionally, results reveal that participants found synchronous tools usable, practical and media-rich. Most of the participants agreed to use these tools in their lifetime especially in their work life since these innovative tools addresses enjoyable learning time and space for students. Reference [66] also supported the importance of the media richness in technology acceptance of e-learning. However, participants declared that they occasionally had hard times with some technical problems such as low speed internet connection. Participants, additionally, notified that synchronous tools and systems need high technical capacity and infrastructure to support uninterrupted effective learning and teaching process. In addition, they stated that using these new systems might also need continuous technical support [67]. 
This research study contributes to the existing literature by examining the attitudes of pre-service teachers toward distance education and examining their technology acceptance status after 4-week synchronous learning intervention. This study extends previous research that investigates technology acceptance status of the learners with quantitative data and contributes to the growing body of research on TAM with its qualitative part. Overall, this study provides a better understanding of individual users' acceptance status and change in their attitude toward distance education. It must be taken into account that though their first use of synchronous distance tools, participants of this study are highly media and computer literate.

\section{References}

[1] Venkatesh, V., Morris, M. G., Davis, G. B., \& Davis, F. D. "User acceptance of information technology: Toward a unified view,"MIS quarterly, 425-478, 2003.

[2] Hrastinski, S. "Asynchronous and synchronous e-learning," Educause quarterly, 31(4), 51-55, 2008.

[3] Kearsley, G., Online Education: Learning and Teaching in Cyberspace, Belmont, CA: Wadsworth, 2000.

[4] Cleveland-Innes, M., \& Ally, M., "Affective learning outcomes in workplace training: A test of synchronous vs. asynchronous online learning environments," Canadian Journal of University Continuing Education, 30(1), 2013.

[5] Sanders, D. W., \& Morrison-Shetlar, A. I., "Student attitudes toward web-enhanced instruction in an introductory biology course," Journal of Research on Computing in Education, 33(3), 251-262, 2001.

[6] Celikkan, U., Senuzun, F., Sari, D., \& Sahin, Y. G., "Interactive Videoconference Supported Teaching in Undergraduate Nursing: A Case Study for ECG,” Educational Technology \& Society, 16(1), 286-294, 2013.

[7] Hsu, L. L., \& Hsieh, S. I., "Factors affecting metacognition of undergraduate nursing students in a blended learning environment," International Journal of Nursing Practice, 20(3), 233-241, 2014.

[8] Bennett, S., \& Lockyer, L., "Becoming an online teacher: Adapting to a changed environment for teaching and learning in higher education,” Educational Media International, 41(3), 231248, 2004.

[9] Beatty, B., \& Ulasewicz, C., "Faculty perspectives on moving from Blackboard to the Moodle learning management system," TechTrends, 50(4), 36-45, 2006.

[10] Britt, R., "Online education: a survey of faculty and students," Radiologic technology, 77(3), 183-190, 2006.

[11] Moore, J. L., Dickson-Deane, C., \& Galyen, K., "E-Learning, online learning, and distance learning environments: Are they the same?,” The Internet and Higher Education, 14(2), 129-135, 2011.

[12] Cox, G., Carr, T., \& Hall, M., "Evaluating the use of synchronous communication in two blended courses," Journal of Computer Assisted Learning, 20(3), 183-193, 2004.

[13] Murphy, E., Rodríguez-Manzanares, M. A., \& Barbour, M., "Asynchronous and synchronous online teaching: Perspectives of Canadian high school distance education teachers," British Journal of Educational Technology, 42(4), 583-591, 2011.

[14] Motycka, C. A., Onge, E. L. S., \& Williams, J. S., “Asynchronous versus synchronous learning in pharmacy education,” Journal of Curriculum and Teaching, 2(1), 2013.

[15] Kumar, S., Johnson, M., \& Hardemon, T., "Dissertations at a Distance: Students' Perceptions of Online Mentoring in a Doctoral Program,” International Journal of E-Learning \& Distance Education, 27(1), 2013.

[16] Hewett, B. L., "Synchronous online conference-based instruction: A study of whiteboard interactions and student writing," Computers and Composition, 23(1), 4-31, 2006.

[17] Kohorst, K., \& Cox, J. R., "Virtual office hours using a tablet PC: E-lluminating biochemistry in an online environment," Biochemistry and Molecular Biology Education, 35(3), 193-197, 2007.
[18] AbuSeileek, A. F., \& Qatawneh, K., "Effects of synchronous and asynchronous computer-mediated communication (CMC) oral conversations on English language learners' discourse functions,” Computers \& Education, 62, 181-190, 2013.

[19] Finkelstein, J., Learning in real time. San Francisco: Jossy-Bass Publishing Company. CA., 2006.

[20] Bower, M., "Synchronous collaboration competencies in webconferencing environments-their impact on the learning process," Distance Education, 32(1), 63-83., 2011.

[21] Picciano, A. G., Distance learning: Making connections across virtual space and time. Upper Saddle River, NJ: Merrill Prentice Hall, 2001.

[22] Palloff, R. M., \& Pratt, K., Building learning communities in cyberspace (Vol. 12). San Francisco: Jossey-Bass, 1999.

[23] Duemer, L., Fontenot, D., Gumfory, K., Kallus, M., Larsen, J., Schafer, S., \& Shaw, B., "The use of online synchronous discussion groups to enhance community formation and professional identity development," The Journal of Interactive Online Learning, 1(2), 1-12, 2002.

[24] Hill, J. R., Song, L., \& West, R. E., "Social learning theory and web-based learning environments: A review of research and discussion of implications," The American Journal of Distance Education, 23(2), 88-103, 2009.

[25] Allmendinger, K., "Social presence in synchronous virtual learning situations: The role of nonverbal signals displayed by avatars,” Educational Psychology Review, 22(1), 41-56, 2010.

[26] Boling, E. C., Hough, M., Krinsky, H., Saleem, H., \& Stevens, M., "Cutting the distance in distance education: Perspectives on what promotes positive, online learning experiences,” The Internet and Higher Education, 15(2), 118-126, 2012.

[27] Im, Y., \& Lee, O., "Pedagogical implications of online discussion for preservice teacher training," Journal of Research on Technology in Education, 36(2), 155-170, 2003.

[28] Branon, R. F., \& Essex, C., "Synchronous and asynchronous communication tools in distance education,” TechTrends, 45(1), 36-36, 2001.

[29] Arbaugh, J. B., “An exploratory study of the effects of gender on student learning and class participation in an Internet-based MBA course,” Management Learning, 31(4), 503-519, 2000.

[30] Mazzolini, M., \& Maddison, S., "Sage, guide or ghost? The effect of instructor intervention on student participation in online discussion forums," Computers \& Education, 40(3), 237-253, 2003.

[31] Wang, S. K., \& Hsu, H. Y., "Use of the webinar tool (Elluminate) to support training: The effects of webinar-learning implementation from student-trainers' perspective," Journal of Interactive Online learning, 7(3), 175-194, 2008.

[32] Moore, M., \& Kearsley, G. Distance education: A systems view (2nd ed.). Belmont, CA: Thomson Wadsworth, 2005.

[33] Ojo, D. O., \& Olakulehin, F. K., "Attitudes and perceptions of students to open and distance learning in Nigeria," The International Review of Research in Open and Distance Learning, 7(1), 2006.

[34] Clark, R. E., "Reconsidering research on learning from media," Review of Educational Research, 53(4), 445-459, 1983.

[35] Kulik, C. L. C., \& Kulik, J. A., "Effectiveness of computer-based instruction: An updated analysis," Computers in Human Behavior, 7(1), 75-94, 1991.

[36] Xenos, M., Pierrakeas, C., \& Pintelas, P. A., "Survey on student dropout rates and dropout causes concerning the students in the course of informatics of the Hellenic Open University," Computers \& Education, 39(4), 361-377, 2002.

[37] Romiszowski, A. J., "How's the e-learning baby? Factors leading to success or failure of an educational technology innovation," Educational Technology, 44 (1), 5-27, 2004.

[38] Venkatesh, V., \& Davis, F. D., "A theoretical extension of the technology acceptance model: four longitudinal field studies," Management science, 46(2), 186-204, 2000.

[39] Carswell, A. D., \& Venkatesh, V., "Learner outcomes in an asynchronous distance learning environment," International Journal of Human-Computer Studies, 56(5), 475-494, 2002.

[40] Legris, P., Ingham, J., \& Collerette, P., "Why do people use information technology? A critical review of the technology acceptance model,” Information \& Management, 40, 191-204, 2003.

[41] Lee, Y., Kozar, K. A \& Larsen, K.R.T., “The technology acceptance model: past, present and future," Communications of the Association for Information Systems, 12 (50), 752-780, 2003. 
[42] Davis, F. D., "Perceived usefulness, perceived ease of use, and user acceptance of information technology,” MIS quarterly, 319340, 1989.

[43] Park, S. Y., "An analysis of the technology acceptance model in understanding university students' behavioral intention to use eLearning," Educational Technology \& Society, 12 (3), 150-162, 2009.

[44] Lee, M. K. O., Cheung, C. M. K., \& Chen, Z., “Acceptance of Internet-based learning medium: The role of extrinsic and intrinsic motivation," Information \& Management, 42, 1095-1104, 2005.

[45] Saadé, R., Nebebe, F., \& Tan, W., "Viability of the" technology acceptance model" in multimedia learning environments: a comparative study,” Interdisciplinary Journal of E-Learning and Learning Objects, 3(1), 175-184, 2007.

[46] Gibson, S. G., Harris, M. L., \& Colaric, S. M., "Technology acceptance in an academic context: Faculty acceptance of online education,” Journal of Education for Business, 83(6), 355-359, 2008.

[47] Gunawardena, C., Lowe, C., \& Carabajal, K., "Evaluating online learning: Models and methods," In Society for Information Technology \& Teacher Education International Conference, pp. 1677-1684, 2000.

[48] Creswell, J. W., \& Clark, V. L. P., Designing and conducting mixed methods research. Thousand Oaks, CA: Sage, 2007.

[49] Tashakkori, A., \& Teddlie, C., Mixed methodology: Combining qualitative and quantitative approaches. Sage. 1998.

[50] Creswell, J. W., Qualitative inquiry and research design: Choosing among five approaches. Sage, 2012.

[51] Ağır, F., Gür, H., \& Okçu, A., "Özel okullarda ve devlet okullarında çalışan ilköğretim öğretmenlerinin uzaktan eğitime karşı tutumlarının belirlenmesi," In The 8th International Educational Technology Conference, pp. 370-375, 2008.

[52] Lincoln, Y. S., \& Guba, E. G., Naturalistic inquiry. Beverly Hills, CA: Sage, 1985.

[53] Marshall, C., \& Rossman, G. B., Designing qualitative research. Sage, 2010.

[54] Yıldırım, A., \& Şimşek, H., Sosyal bilimlerde nitel arastirma yöntemleri. Seçkin Yayıncılık, 2006.

[55] Park, Y. J., \& Bonk, C. J., "Synchronous learning experiences: Distance and residential learners' perspectives in a blended graduate course," Journal of Interactive Online Learning, 6(3), 245-264, 2007

[56] Johnson, G., "The relative learning benefits of synchronous and asynchronous text-based discussion," British Journal of Educational Technology, 39(1), 166-169, 2008.

[57] Annetta, L., Murray, M., Gull Laird, S., Bohr, S., \& Park, J., "Investigating student attitudes toward a synchronous, online graduate course in a multi-user virtual learning environment," Journal of Technology and Teacher Education,16(1), 5-34, 2008.
[58] Beyth-Marom, R., Saporta, K., \& Caspi, A., "Synchronous vs. asynchronous tutorials: Factors affecting students' preferences and choices," Journal of Research on Technology in Education, 37(3), 245-262, 2005.

[59] Akarasriworn, C., \& Ku, H. Y., "Graduate Students' Knowledge Construction and Attitudes Toward Online Synchronous Videoconferencing Collaborative Learning Environments," Quarterly Review of Distance Education, 14(1), 2013.

[60] Bernard, R. M., Abrami, P. C., Lou, Y., Borokhovski, E., Wade, A., Wozney, L., Wallet, P. A., Fiset, M. \& Huang, B., "How does distance education compare with classroom instruction? A metaanalysis of the empirical literature," Review of Educational Research, 74(3), 379-439, 2004.

[61] Kear, K., Chetwynd, F., Williams, J., \& Donelan, H., "Web conferencing for synchronous online tutorials: Perspectives of tutors using a new medium," Computers \& Education, 58(3), 953963, 2012.

[62] McBrien, J. L., Cheng, R., \& Jones, P., "Virtual spaces: Employing a synchronous online classroom to facilitate student engagement in online learning," The International Review of Research in Open and Distance Learning, 10(3), 1-17, 2009.

[63] Chao, K. J., Hung, I. C., \& Chen, N. S., "On the design of online synchronous assessments in a synchronous cyber classroom," Journal of Computer Assisted Learning, 28(4), 379-395, 2012.

[64] Kuo, Y. C., Walker, A. E., Belland, B. R., Schroder, K. E., \& Kuo, Y. T., "A case study of integrating Interwise: Interaction, internet self-efficacy, and satisfaction in synchronous online learning environments," The International Review of Research in Open and Distance Learning, 15(1), 164-181, 2014.

[65] Oztok, M., Zingaro, D., Brett, C., \& Hewitt, J., "Exploring asynchronous and synchronous tool use in online courses," Computers \& Education, 60(1), 87-94, 2013.

[66] Liu, S. H., Liao, H. L., \& Pratt, J. A., "Impact of media richness and flow on e-learning technology acceptance," Computers \& Education, 52(3), 599-607, 2009.

[67] Marjanovic, O., "Learning and teaching in a synchronous collaborative environment," Journal of Computer Assisted Learning, 15(2), 129-138, 1999.

[68] Hart, C., "Factors associated with student persistence in an online program of study: A review of the literature," Journal of Interactive Online Learning, 11(1), 19-42, 2012.

[69] Harrell, I. L., \& Bower, B. L., "Student characteristics that predict persistence in community college online courses," American Journal of Distance Education, 25(3), 178-191. 2011.

[70] Musingafi, M. C., Mapuranga, B., Chiwanza, K., \& Zebron, S., "Challenges for Open and Distance learning (ODL) Students: Experiences from Students of the Zimbabwe Open University" Journal of Education and Practice, 6(18), 59-66, 2015.

[71] Goodwin, L. D., \& Goodwin, W. L. (1984). Are validity and reliability "relevant" in qualitative evaluation research? Evaluation \& the Health Professions, 7, 413-426. 